\title{
DUPLEX SONOGRAPHY FINDINGS IN ESTABLISHED CASES OF DIABETIC NEPHROPATHY- A DESCRIPTIVE STUDY OVER A PERIOD OF SIX MONTHS
}

\author{
Rajiv Kumar1, Mozammil Hassan², Raunak Deo3, Kousik Mandal', Kumar Abhinav ${ }^{5}$ \\ ${ }_{1}^{1}$ Associate Professor, Department of Radiology, Patna Medical College and Hospital, Bihar. \\ 2Junior Resident, Department of Radiology, Patna Medical College and Hospital, Bihar. \\ 3 Junior Resident, Department of Radiology, Patna Medical College and Hospital, Bihar. \\ 4Junior Resident, Department of Radiology, Patna Medical College and Hospital, Bihar. \\ 5Junior Resident, Department of Medicine, Patna Medical College and Hospital, Bihar.
}

\section{ABSTRACT}

\section{BACKGROUND}

Diabetic nephropathy (Nephropatia diabetica) also known as Kimmelstiel-Wilson syndrome and intercapillary glomerulonephritis, is a progressive kidney disease caused by angiopathy of capillaries in kidney glomeruli. It is characterised by nephrotic syndrome and nodular glomerulosclerosis. It is due to longstanding diabetes mellitus and is a prime cause of dialysis in modern society. Objectives - To elucidate different duplex sonographic findings in patients presenting with diabetic nephropathy.

\section{MATERIALS AND METHODS}

A six-month descriptive study was conducted from December 2016 to May 2017 and data on findings of duplex sonography was obtained. Patients with established diagnosis of diabetic nephropathy presented in Department of Radiology at Patna Medical College and Hospital, Patna from December 2016 to May 2017 were included in the present study. A total of 76 patients presented to our department between the given period of time who then underwent duplex sonography scan, performed by one of experienced radiologist in our department. The inclusion criteria for analysis were the patients who had biochemically proven albuminuria i.e. urine albumin $>30 \mathrm{mg} /$ day on at least 2 days 3 to 6 months apart and elevated serum creatinine value i.e. serum creatinine $>1.5 \mathrm{mg} / \mathrm{dL}$. All the patients underwent duplex Doppler for bilateral kidneys. USG \& Colour Doppler study is carried out by GE Logiq P3 model of USG machine using 4-5.5 MHz \& 7.5-12 MHz probe.

\section{RESULTS}

76 patients were studied with established diagnosis of diabetic nephropathy with a mean age of 50.6 yrs. \pm 10.8 (range 31 yrs. to 70 yrs.). In our study, all the 76 patients had albuminuria and deranged serum creatinine levels i.e.> $1.5 \mathrm{mg} / \mathrm{dL}$. The results were interpreted in the form of number of kidneys analysed. Out of 152 kidneys, 106 kidneys (69.7\%) showed increased resistivity index, 64 kidneys (42.1\%) showed attenuation of the corticomedullary differentiation, 47 (30.9\%) kidneys showed either renal cysts or dystrophic calcification or both. 28 kidneys (18.4\%) had neither attenuated corticomedullary (CMD) differentiation nor raised resistivity index value.

\section{CONCLUSION}

Duplex Doppler provides an easily applicable, non-invasive, and well-established method for investigating renal morphologic characteristics, diagnosing renal artery stenosis, and measuring vascular resistance in the renal parenchyma. The resistive index measured by duplex Doppler is used as an indicator of underlying renal pathology and progression of the disease.

\section{KEYWORDS}

Resistive Index, Duplex Doppler, Diabetic Nephropathy.

HOW TO CITE THIS ARTICLE: Kumar R, Hassan M, Deo R, et al. Duplex sonography findings in established cases of diabetic nephropathy- A descriptive study over a period of six months. J. Evolution Med. Dent. Sci. 2017;6(61):4475-4477, DOI: $10.14260 /$ Jemds/2017/967

\begin{tabular}{|c|c|}
\hline \multicolumn{2}{|r|}{$\begin{array}{l}\text { Diabetic nephropathy is a microvascular comp } \\
\text { Diabetes Mellitus characterised by glomeru } \\
\text { arteriolar hyalinosis \& interstitial fibrosis. These } \\
\text { associated with clinical syndrome of } \\
\text { hypertension \& progressive renal failure. }{ }^{1}\end{array}$} \\
\hline & 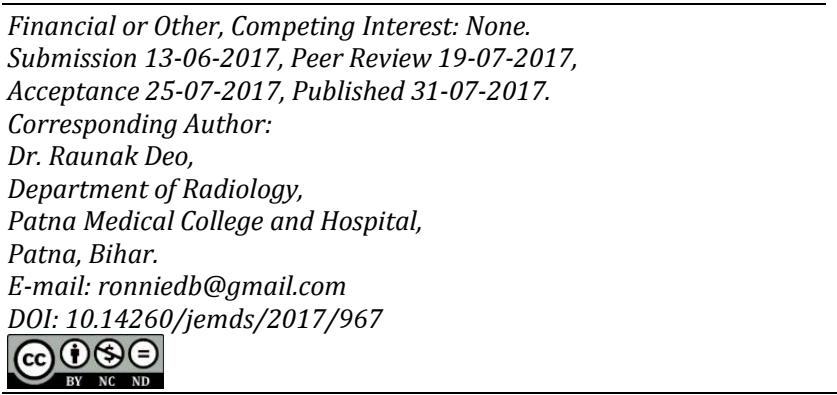 \\
\hline
\end{tabular}
at least 2 occasions 3-6 months apart, progressive decline in GFR \& elevated serum creatinine level $(>1.5 \mathrm{mg} / \mathrm{dL})$. Value of 24-hour urinary albumin excretion ranging from $30-300 \mathrm{mg}$ is considered microalbuminuria; whereas value $>300 \mathrm{mg} /$ day is considered clinical albuminuria.

Resistive indices by Duplex Doppler Ultrasonography predicts renal functional status in diabetic patients \& also causing early detection of diabetic nephropathy. ${ }^{2}$ Hence, it provides numerical parameter for evaluating renal functional status. Average RI value in intrarenal artery lies between $0.53-0.68$. If RI value is equal or above 0.7 , it is considered to be abnormal. ${ }^{3}$

Histopathological changes affect mainly the vascular compartments in the kidneys of diabetic patients. ${ }^{4}$ Intrarenal $\mathrm{RI}$ is a measure of haemodynamic changes in the renal arteries, manifested by its increased value. Renal RI correlated highly with serum creatinine level \& creatinine 
clearance rate. $^{2}$ Increased renal RI strongly predicts the course \& outcome of renal function in type 2 DM with microalbuminuria. 5

\section{MATERIALS AND METHODS}

A six-month descriptive study was conducted from December 2016 to May 2017 and data on findings of duplex sonography was obtained. Patients with established diagnosis of diabetic nephropathy presented in the Department of Radiology at Patna Medical College and Hospital, Patna from December 2016 to May 2017 were included in the present study. A total of 76 patients presented to our department between the given period of time who then underwent duplex sonography scan, performed by one of experienced radiologist in our department. The inclusion criteria for analysis were patients who had biochemically proven albuminuria i.e. urine albumin $>30 \mathrm{mg}$ /day on at least 2 days 3 to 6 months apart and elevated serum creatinine value i.e. serum creatinine $>1.5$ $\mathrm{mg} / \mathrm{dL}$. All the patients underwent duplex Doppler for bilateral kidneys. USG \& Colour Doppler study is carried out by GE Logiq P3 model of USG machine using 4-5.5 MHz \& 7.5$12 \mathrm{MHz}$ probe. An informed consent was taken from all the patients. All patients had consented for using the data for publications.

Our study population comprised of 76 diabetic nephropathy patients having gender distribution of 49 male \& 27 female subjects, ranging from age group of 31 to 70 years. The results have been interpreted according to the number of kidneys analysed, so for 76 patients we analysed both the kidneys which amounts to 152 kidneys.

All patients underwent ultrasound scan and renal Doppler scan for both the kidneys. The findings were categorised under three headings as follows:

1. Raised intraparenchymal renal artery resistivity index (RI), the criteria for which was taken as RI value $>0.70$.

2. Attenuation of corticomedullary (CMD) differentiation.

3. Other findings, which included presence of renal cysts and/or dystrophic calcification.

\section{Statistical Analysis}

Microsoft office 2010 was used for the statistical analysis. Mean and percentage were used to interpret the data.

\section{RESULTS}

Seventy six patients were studied with established diagnosis of diabetic nephropathy with a mean age of 50.6 yrs. \pm 10.8 (range 31 yrs. to 70 yrs.). In our study, all the 76 patients had albuminuria and deranged serum creatinine levels i.e.> 1.5 $\mathrm{mg} / \mathrm{dL} .45$ out of 76 patients presented with facial oedema, 32 patients had bilateral pedal oedema. 28 of these patients were undergoing dialysis. Out of 76 patients, 52 had microalbuminuria (i.e. 24-hour urine albumin $>30 \mathrm{mg} /$ day but less than $300 \mathrm{mg} /$ day), and rest of the 24 patients had clinical albuminuria (i.e. 24-hour urine albumin $>300$ $\mathrm{mg} /$ day). 12 of the 76 patients were diagnosed with endstage renal disease and all these patients showed complete loss of corticomedullary differentiation with shrunken kidneys.

The results were interpreted in the form of number of kidneys analysed. Out of 152 kidneys, 106 kidneys (69.7\%) showed increased resistivity index, 64 kidneys (42.1\%) showed attenuation of the corticomedullary differentiation,
47 (30.9\%) kidneys showed either renal cysts or dystrophic calcification or both. 28 kidneys (18.4\%) had neither attenuated corticomedullary (CMD) differentiation nor raised resistivity index value. Out of 64 kidneys which showed CMD attenuation, only 6 of the kidneys had normal value of RI values. Out of 106 kidneys which showed raised RI value, 88 had RI value in the range of 0.70 to $0.80,12$ had RI in the range of 0.80 to 1.0 and 6 of them had RI value more than 1.0.

The age of the patients in our study ranged from 31 to 70 years. Out of 76 patients, 49 were female and 27 were male. All the patients hailed from gangetic belt.

\section{Ultrasound Scan and Duplex Doppler Findings}

\begin{tabular}{|c|c|c|c|c|}
\hline $\begin{array}{c}\text { Age } \\
\text { Group } \\
\text { (Yrs.) }\end{array}$ & $\begin{array}{c}\text { No. of } \\
\text { Kidneys }\end{array}$ & $\begin{array}{c}\text { Kidneys with } \\
\text { Increased RI } \\
\text { Value }\end{array}$ & $\begin{array}{c}\text { Kidneys with } \\
\text { Attenuated } \\
\text { CMD }\end{array}$ & $\begin{array}{c}\text { Other } \\
\text { Findings }\end{array}$ \\
\hline $31-40$ & 28 & $14(9.2 \%)$ & $14(9.2 \%)$ & $5(3.2 \%)$ \\
\hline $41-50$ & 52 & $42(27.6 \%)$ & $12(7.8 \%)$ & $8(5.2 \%)$ \\
\hline $51-60$ & 38 & $30(19.7 \%)$ & $28(18.4 \%)$ & $14(9.2 \%)$ \\
\hline $61-70$ & 34 & $20(13.1 \%)$ & $10(6.5 \%)$ & $20(13.1 \%)$ \\
\hline Total & $\mathbf{1 5 2}$ & $\mathbf{1 0 6}(\mathbf{6 9 . 7 \% )}$ & $\mathbf{6 4 ( 4 2 . 1 \% )}$ & $\mathbf{4 7}(\mathbf{3 0 . 9 \% )}$ \\
\hline
\end{tabular}

\section{DISCUSSION}

Advancements in Duplex sonography assist radiologists in diagnostic radiology.

A high proportion of patients with type 2 diabetes are found to have microalbuminuria and overt nephropathy shortly after the diagnosis of diabetes because diabetes is usually present for many years before the diagnosis and also because the presence of albuminuria might be less specific for the presence of diabetic nephropathy, as shown by biopsy studies. ${ }^{6-9}$ Without proper treatments, $20 \%$ to $40 \%$ of type 2 diabetic patients with microalbuminuria progress to overt nephropathy. If pharmacological intervention is started even before the onset of proteinuria, the progression of the disease to overt nephropathy could be controlled.10

Duplex Doppler is an easily available diagnostic test which is non-invasive in nature and is very helpful in assessing the renal morphology, diagnosing renal artery stenosis, and analysing the resistance within the intrarenal artery.11-14 The renal resistive index (RI), measured by duplex sonography, has been shown to be associated with features of diabetic nephropathy and its progression over time, independent of albuminuria, ${ }^{15}$ and in a multivariate regression analysis, the RI was an independent predictor of declining renal function. ${ }^{16}$ Raised RI value is a strong indicator of increased resistance of intrarenal artery which is a result of scarring and fibrosis of the renal tissue which leads to the reduction of area of vascular bed. ${ }^{15}$

Another study ${ }^{17}$ showed the Mean RI value as $0.69 \pm 0.1$ in patients with diabetes. Patients with established nephropathy had a Mean RI of $0.83 \pm 0.115$.

\section{CONCLUSION}

Changes in renal haemodynamics are detectable on sonography in diabetic patients. These changes are mainly seen in the form of raised RI value which is also accompanied by altered corticomedullary differentiation. However, not all the patients with albuminuria present with raised RI values or CMD attenuation on duplex sonography. 


\section{REFERENCES}

[1] Ritz E, Orth SR. Nephropathy in patients with type 2 diabetes mellitus N Engl J Med 1999;341(15):112733.

[2] Platt JF, Rubin JM, Ellis JH. Diabetic nephropathy: evaluation with renal duplex Doppler ultrasonography. RSNA Radiology 1994;190(2):343-6.

[3] Soldo D, Brkljacic B, Bozikov V, et al. Diabetic nephropathy. Comparison of conventional and duplex Doppler and ultrasonographic findings. Acta Radiol 1997;38(2):296-302.

[4] Milovanceva-Popovska M, Dzikova S. Progression of diabetic nephropathy: value of intrarenal resistive index (RI). Prilozi 2007;28(1):69-79.

[5] Hamano K, Nitta A, Ohtake T, et al. Associations of renal vascular resistance with albuminuria and other macroangiopathy in type 2 diabetic patients. Diabetes Care 2008;31(9):1853-7.

[6] Molitch ME, DeFronzo RA, Franz MJ, et al. Nephropathy in diabetes. Diabetes Care 2004;27(Suppl 1)S79-S83.

[7] Bakris GL, Williams M, Dworkin L, et al. Preserving renal function in adults with hypertension and diabetes: a consensus approach. National Kidney Foundation Hypertension and Diabetes Executive Committees Working Group. Am J Kidney Dis 2000;36(3):646-61.

[8] Gross JL, de Azevedo MJ, Silveiro SP, et al. Diabetic nephropathy: diagnosis, prevention and treatment. Diabetes Care 2005;28(1):164-76.
[9] Mogensen CE, Keane WF, Bennett PH. Prevention of diabetic renal disease with special reference to microalbuminuria. Lancet 1995;346(8982):1080-4.

[10] Ruggenenti P, Fassi A, Ilieva AP, et al. Preventing microalbuminuria in type 2 diabetes. $\mathrm{N}$ Engl J Med 2004;351(19):1941-51.

[11] Krumme B, Blum U, Schwertfeger E, et al. Diagnosis of renovascular disease by intra-and extrarenal Doppler scanning. Kidney Int 1996;50(4):1288-92.

[12] Pape L, Offner G, Ehrich JH. Renal arterial resistance index. N Engl J Med 2003;349(16):1573-4.

[13] Radermacher J, Mengel M, Ellis S, et al. The renal arterial resistance index and renal allograft survival. $\mathrm{N}$ Engl J Med 2003;349(2):115-24.

[14] Zierler RE, Bergelin RO, Isaacson JA, et al. Natural history of atherosclerotic renal artery stenosis: a prospective study with duplex ultrasonography. J Vasc Surg 1994;19(2):250-8.

[15] Masuli M, Mancini M, Liuzzi R, et al. Measurement of the intrarenal arterial resistance index for the identification and prediction of diabetic nephropathy. Nutr Metab Cardiovasc Disease 2009;19(5):358-64.

[16] Radermacher J, Ellis S, Haller H. Renal resistance index and progression of renal disease. Hypertension 2002;39(2 Pt 2):699-703.

[17] Sari A, Dinc H, Zibandeh A, et al. Value of resistive index in patients with clinical diabetic nephropathy. Invest Radiol 1999;34(11):718-21. 